\title{
Analysis of the College Information Disclosure System
}

\author{
Eunjoo Oh \\ Kyungil University \\ eoh1@hanmail.net
}

\begin{abstract}
The purpose of this study is to analyze how the consumers perceive information disclosure systems and how they are utilizing the information provided. To achieve the study purposes, this study analyzed the user database of the College Alimi website, conducted recognition and satisfaction surveys on information disclosure with the college students and high school teachers. In addition, interviews with college professors were conducted as well. Based on the study results, how information users such as students, teachers, and professors perceive and utilize the information and suggestions were made for the better use of the system.
\end{abstract}

Keywords: Educational Information, Information Disclosure, Information Consumers

\section{Introduction}

\subsection{Background}

Modern society is an information society in which knowledge and information form the backbone of society and the economy. One of the defining characteristics of an information society is that the speed at which information is created, distributed, and consumed is extremely rapid. Advanced technologies have simplified access to information and facilitated the disclosure of information that fulfills people's right to know. As the demand for a diversity of information increases, private and government organizations started to open a range of information to the public. It made information users access to the necessary information more easily and quickly. Similar trends can be seen in the field of education; since the enactment of the Act on the Disclosure of Educational Information on May 26, 2007, elementary schools, middle schools, high schools, and universities have been required to disclose educational information. From the perspective that information related to education is a public good, these disclosure systems provide educational consumers with required information and education institutions fulfill their responsibilities as public organizations.

According to the enactment, the ministry of education decided the categories and items to open the public and developed the website called Alimi to provide information of higher education institutions. Currently, disclosed information includes 64 items in 14 categories such as institutional operations, students, staff, research, budgets, and educational environment. Since the website was developed in 2007, contents and categories have been revised and modified to ensure the quality of information. Policies for higher education information disclosure mandate the regular disclosure of information possessed by higher education institutions. Disclosure presents many benefits: educational consumers, such as the parents of students, students, and business organizations, are able to access the information they require at any given time and comprehensively understand and make decisions regarding higher education institutions. The government is also able to gather data required for setting policy quickly. 
The Alimi system is highly effective from the perspective that it formally legislates educational information disclosure and the policy-related utilization of this disclosed information. However, researches on the Alimi system (Ko, 2014; Park et al., 2010; Park, 2013; Ahn et al., 2013). Ko (2014) and Ahn et al. (2013) have claimed that there are some issues in using the system. For example, information users have been limited to the government officials and college staff. They use the information to assess the performance of colleges and educational organization and thus, only certain types of information used for the assessment were retrieved from the system (Ko, 2014; Ahn et al. (2013). Park et al. (2010) also pointed out that since the colleges record their own information by themselves, reliability of information is questionable. In reality, when examining the Q\&A section of the Alimi website, the information users complain that it is difficult for general users to retrieve the data as they intend to. In detail they complain that "It is difficult to compare faculties," "It is difficult to comparatively search information as the information is provided in PDF form and cannot be exported to Excel," "There are frequent errors in the detailed search for institutions," and that "There are errors in the search results of major indicators." However, most of the information in Alimi is being converted to Excel and the detailed search enables users to compare information by faculty and by institution. The reason why these difficulties arise is because information users do not understand how to utilize the system properly.

\subsection{Need of the Study}

The Alimi system should be composed of elements that users need. When it does not fulfill consumers' right to know, the system should be revised $(K o, 2014)$. The purpose of the Alimi system is to quickly and accurately provide key information on higher education institutions to students, their parents, business organizations, and the government. It provides information about the general operations of the colleges and its education and research capabilities. With the information provided, students and parents can choose the college to attend and business organizations can decide recruitment of students, and the government can decide financial support for the colleges. Hence, it is necessary to examine whether the Alimi system is being properly perceived and used to provide information to various user groups, and whether users are satisfied with the information system.

\subsection{Purpose of the Study}

The purposes of this study are to analyze how the consumers perceive the Alimi and how they are utilizing the information provided. To achieve these purposes, this study examined the use of the Alimi site by analyzing the visitors' database from the year of 2001 to 2005. In addition, surveys with college students and high school teachers were conducted and interviews with college professors were conducted to examine how they perceive and utilize the system.

\section{College Information Disclosure Systems in Other Countries}

When examining the information disclosure systems in other countries, operating methods of disclosure system in Japan and United Kingdom are similar to Korea. Japan has a similar educational system as Korea, and United Kingdom has regulations pertaining to education mandate for disclosure of information.

\subsection{Japan}

Japan passed relevant regulations on education information disclosure in 2001, which were enacted into law and relevant enforcement orders in 2002; education information is disclosed on each institution's own website. The regulations relating to education 
information disclosure are primarily oriented toward improving education and clarifying, in a legal manner, what information should be revealed by higher education institutions as public educational institutions that have a responsibility for explaining their activities to society. Under the Education Act (Clause 172, 2, Sub-clause 1 Relationship), higher education institutions (including professional colleges and graduate schools) are mandated to reveal information on education and research activities on their own websites. However, basic information on institutional and staff operations is provided in the section pertaining to educational statistics on the website of Ministry of Education, Culture, Sports, Science and Technology (MEXT); information for job-seekers is placed on each institution's own website with support from the Ministry of Labour, Health and Welfare (MHLW). The webpage shows information that is being disclosed in the manner mandated by the Education Act. The information on employment rates from higher education institutions provided by MEXT. Employment rates are disclosed on the MEXT webpage with data from MHLW.

\subsection{United Kingdom}

In the case of United Kingdom, the Freedom of Information Act, which came into be effective in 2005, mandates that information from all educational institutions, including higher education institutions, is disclosed. Information required to be disclosed is determined by the government; the Higher Education Statistics Agency (HESA), through the Higher Education Database for Institutions (HEIDI), gathers this information and provides to the government (Higher Education Funding Council for England, HEFCE) and the agency responsible for budget allocation to higher education institutions. Similar to Korea, it is mandated that institutions themselves are responsible for inputting information within a certain period of time; furthermore, to ensure the accuracy of the disclosed information, institutions are required to undergo a strict review process. The final results of information gathering are provided online in the form of a publication for governments and general consumers; online data is provided at no cost but the publication is available for purchase. The disclosed information pertains to students, staff, post-graduate aspirations, finances, regional and industry collaboration, and the management of school grounds.

\subsection{Comparison between Countries}

In the cases of Japan and United Kingdom, from the perspective of the citizens' right to know and the responsibility of higher education institutions, information pertaining to higher education is being actively disclosed. However, unlike on the Alimi website, this information is not revealed comprehensively or systematically in one place to be managed structurally; moreover, the information provided is not free of charge, nor as diverse and specific as on the ALIMI website. In the case of Japan, each institution provides its own information in the form of webpages or text; focused information that allows for easy comparisons is difficult to find. The educational statistics provided by Ministry of Education are limited to employment and job-seeking and in order to find specific information pertaining to institutions and faculties, users must visit institutional websites.

In the case of the United Kingdom, similar to Korea, data is gathered and disclosed through HESA and HEDI, which are the main agents for operating and maintaining educational information, resulting in the provision of comprehensive information. However, these data are provided online in the form of Excel spreadsheets, unlike in the Korean disclosure system, where users can select categories and compile information. The Alimi website in Korea enables users to select and download necessary information through a database; the final results can be exported to Excel. The Alimi data can be selected on the basis of indicators - by year per category, by institution, and by facility; this allows for comparing information depending on the user's preferences and detailed 
information pertaining to the operations of an institution can be exported to Excel. Moreover, information disclosure is mandated by law and is utilized for policy assessment purposes, thus requiring accuracy; each year, new guidelines on using the Alimi website are published online. This is because Korea has a very high interest in education and the government attempts to fulfill citizens' right to know and the demand for information through large budget allocations to acquiring information. Despite these attempts, many studies (Ko, 2014; Lee, 2011) have identified problems with the utilization of the disclosed information. Therefore, it is necessary to understand how much information consumers understand about this higher education information disclosure policy and how they utilize the disclosed information.

\section{Methodology}

\subsection{Study Participants}

282 university students and 20 high school teachers participated in this study. The university students included 226 freshmen and 56 juniors enrolled at $\mathrm{Y}$ University and $\mathrm{N}$ University in the K region; 20 teachers responsible for college admissions for seniors at a high school in the $\mathrm{K}$ region also participated in the survey. In order to determine whether they utilized the Alimi website during the college admissions process, a sample consisting of university students and high school teachers directing college admissions was chosen; in order to see if the results differed for students in different years in university, both freshmen and juniors were sampled. A total of five participants from $\mathrm{N}$ University participated in the group interview, including three engineering professors, one liberal arts professor, and one health sciences professor.

\subsection{Study Methods}

This study analyzed a visiting history database, and surveys and interviews were conducted; in order to confirm the current state of information utilization, a database that recorded the frequency of visits by Alimi website users was analyzed and surveys with the university students and high school teachers were conducted. Furthermore, a group interview was conducted with five university professors. The group interview consisted of open-ended questions on information disclosure related to the recognition, utilization, necessity, and ease of data utilization.

\subsection{Study Tools}

As study tools, surveys and the visiting history database for the Alimi website were used. The data from the database included visiting history data from 2010-2013 (gathered in 2013), from 2011-2014 (gathered in 2014), and from 2012-2015 (gathered in 2015). A survey targeting students and teachers was created by the researcher and confirmed by three experts on education administration for validity; the survey consisted of five questions on recognition, five questions on utilization, five questions on necessity, and five questions on the ease of data utilization, totaling 20 questions in four categories. Reliability was measured and was very high at 0.96 .

\section{Data Analysis}

\subsection{Current State of Alimi Data Use}

In order to determine how much the Alimi data were used, the visiting history database for the Alimi website was analyzed. The data from the database included visiting history from 2010-2013 (as gathered in 2013), from 2011-2014 (as gathered in 2014), and from 2012-2015 (as gathered in 2015). The 2015 data consisted of data from January to June. In 
this study, accumulated hits data from 2010-2013, 2011-2014, and 2012-2015 are referred to as 2013,2014 , and 2015 data, respectively.

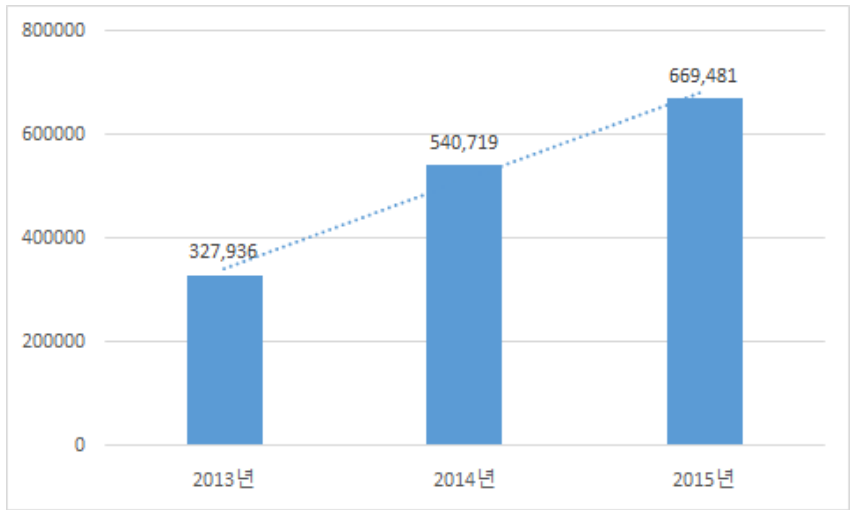

Figure 1. The Use of Alimi Data from the Year of 2013 to 2015

4.1.1. Total Number of Search Hits of the Alimi Data: Per the analysis of the number of view hits of the Alimi data, the number of hits increased every year, with 327,936 hits in 2013, 54,079 hits in 2014, and 669,481 hits in 2015. Despite the fact that the 2015 data consisted of data from January to June, it showed an increase over 2014, indicating that data utilization had rapidly increased.

4.1.2. Monthly Number of Search Hits: When the number of hits for the Alimi website was analyzed on a monthly basis, April exhibited the most hits with 476,620 hits; July $(76,120)$, February $(81,565)$, and March $(86,640)$ showed a significantly smaller number of hits compared to other months. When the monthly number of hits was analyzed by research year and year of data formulation, in 2013, June, July, and August showed a substantially larger number of hits for 2012 information, though these numbers declined after August and 2013 information was more intensively searched for after June. In 2014, August, September, and October showed a substantially larger number of hits in August, September, and October. According to the analysis of 2015 hits data, an anomaly was found as the 2015 information was viewed 390,740 times in April, a significantly higher number of hits compared to other months.

\subsection{Analysis of Number of Search Hits by Items}

4.2.1. Top and Bottom 10 Items by Number of Search Hits: According to the analysis of the number of search hits by item, in 2013 and 2014, the status of tuition had the highest number of search hits, whereas the student dropout rates had the highest number of search hits in 2015. These items had been searched for the most. According to the 2013 data, the employment status of graduates, employment status of new students, research track record of institution staff, status of current students, and student enrolment rates were viewed the most. In 2014, the employment status of graduates, status of freshmen enrolment, share of staff in classes, status of current students, and research track record of staff were the most viewed; in 2015, the status of tuition, employment status of graduates, status of freshmen enrolment, research track record of staff, and status of current students were the most viewed. Overall, the information relating to enrolment and continued attendance, such as in regard to tuition, enrolment, maintenance of enrollment, and employment postgraduation, were the most viewed.

Based on the analysis of monthly hits for the top three viewed items, viewing trends were similar to overall hits. According to the 2013 research data, the status of tuition was viewed the most in August and December, the employment status of graduates was viewed 
the most in September, and freshmen enrolment was viewed the most in July. According to the research data from 2014, the status of tuition was viewed the most in September and December and the employment status of graduates and the status of freshmen enrolment were viewed the most in September. As previously mentioned, in the 2015 research data, the number of view hits for the status of dropout students $(380,123)$ was anomalously high in April. The 10 least viewed items included items related to budget and settlement of accounts, tuition accounting, meeting minutes of the tuition committee, the criteria for determining educational fees per student, the status of enrolment screening fees, entrepreneurship support for staff, and management of dormitories.

\subsection{Analysis of Survey Results}

4.3.1. Results of the Student Survey: Surveys were conducted with university students and high school teachers that were responsible for college admissions counseling to determine if they had utilized the data disclosed in Alimi for university entrance; it was found that the disclosed information was rarely used for university entrance because students had little recognition of the website. Regarding recognition of the Alimi website, average scores were very low: among the university students and teachers, average scores were 1.56 and 2.25 , respectively. The university students had barely heard of the Alimi website and they did not understand the items and indicators on the website. As for the teachers, while they had heard of the Alimi website, they had not heard of the items and the indicators on the website.

Table 1. Perceptions of Alimi

\begin{tabular}{|c|c|c|c|c|c|}
\hline & \multirow{2}{*}{ Perceptions of Alimi } & \multicolumn{2}{|c|}{ Students } & \multicolumn{2}{|c|}{ Teachers } \\
\hline & & M & M & S.D & M \\
\hline 1 & I am aware of Alimi site. & 1.74 & 1.03 & 2.85 & 1.69 \\
\hline 2 & I am aware of the items in the Alimi system. & 1.40 & 0.71 & 2.05 & 1.15 \\
\hline 3 & I am aware of 40 indicators of information disclosure. & 1.41 & 0.71 & 1.95 & 1.19 \\
\hline 4 & $\begin{array}{l}\text { I am aware of foreign countries which disclose educational } \\
\text { information. }\end{array}$ & 1.43 & 0.77 & 1.90 & 1.29 \\
\hline \multirow[t]{2}{*}{5} & Alimi provide accurate information about colleges. & 1.84 & 1.03 & 2.50 & 1.04 \\
\hline & Averages & 1.56 & 0.85 & 2.25 & 1.27 \\
\hline
\end{tabular}

When analyzing the utilization of Amili, among university students and high school teachers, average scores were found to be 1.8 and 2.4, respectively, showing that neither group had had much experience in utilizing the site. While the university students believed that the information was not useful to incoming freshmen in choosing institutions, the teachers believed that the site was somewhat useful $(m=2.6)$. Neither group believed that the data from Alimi could be utilized to compare institutions' capabilities or to analyze institutions.

Table 2. Utilization of Alimi

\begin{tabular}{llcccc}
\hline & & \multicolumn{2}{c}{ Utilization of Amili } & \multicolumn{2}{c}{ Teachers } \\
\cline { 3 - 6 } & & $\mathrm{M}$ & $\mathrm{S} . \mathrm{D}$ & $\mathrm{M}$ & S.D \\
\hline 1 & I have experiences using Alimi. & 1.57 & 0.93 & 2.15 & 1.49 \\
2 & I can compare data among the colleges & 1.90 & 1.05 & 2.40 & 1.04 \\
3 & It is useful to make a decision for selecting the college. & 1.70 & 1.01 & 2.60 & 1.14 \\
4 & It is useful for administrators to make decisions. & 1.95 & 1.11 & 2.53 & 1.07
\end{tabular}


Alimi provides information necessary to know the colleges.

$\begin{array}{llll}1.87 & 1.06 & 2.32 & .94 \\ 1.80 & 1.03 & 2.40 & 1.14\end{array}$

When analyzing the need of Alimi, both the university students and the high school teachers agreed that information disclosure was necessary. Specifically, the students $(\mathrm{m}=2.59)$ and the teachers $(\mathrm{m}=3.05)$ believed that information disclosure was needed from the perspective of evaluating the responsibility of education and for evaluating the transparency and efficiency of institutional operations $(\mathrm{m}=2.58$ and $\mathrm{m}=3.3$, respectively). Moreover, the information disclosure system fulfills the students and their parents' right to know ( $\mathrm{m}=2.63, \mathrm{~m}=2.95$, respectively) and is required from the perspective that it enhances the citizen participation in higher education $(\mathrm{m}=2.51$ and $\mathrm{m}=3$, respectively).

\section{Table 3. Need of Alimi}

\begin{tabular}{llcccc}
\hline & \multicolumn{1}{c}{ Need of Alimi } & \multicolumn{2}{c}{ Students } & \multicolumn{2}{c}{ Teachers } \\
\cline { 2 - 6 } & $\mathrm{M}$ & S.D & $\mathrm{M}$ & S.D \\
\hline 1 & I agree to implement the information disclosure system. & 2.58 & 1.25 & 3.00 & 1.49 \\
& $\begin{array}{l}\text { Alimi is necessary for the colleges to be more responsible for } \\
\text { their roles as public orgranizations. }\end{array}$ & 2.59 & 1.21 & 3.05 & 1.54 \\
3 & $\begin{array}{l}\text { Alimi plays a role to fulfill the rights to know for public. } \\
4\end{array}$ & 2.63 & 1.25 & 2.95 & 1.43 \\
$\begin{array}{l}\text { Alimi increases the chances to participate in the information } \\
\text { related activities. }\end{array}$ & 2.51 & 1.18 & 3.00 & 1.49 \\
& $\begin{array}{l}\text { Alimi is necessary for the higher education institutions to } \\
\text { manage fairly. }\end{array}$ & 2.58 & 1.23 & 3.30 & 1.53 \\
& Averages & 2.58 & 1.22 & 3.06 & 1.49 \\
\hline
\end{tabular}

In terms of ease of access, both students and teachers responded that the Alimi website was difficult to use; the average response value was 2.2. Both students and teachers reported that accessing the site was difficult, that comparing data by institution and by faculties was difficult, and that accurate explanations and guidelines for the information disclosure websites were unavailable.

Table 4. Ease of Access

\begin{tabular}{llcccc}
\hline \multirow{2}{*}{ Ease of Access } & \multicolumn{2}{c}{ Students } & \multicolumn{2}{c}{ Teachers } \\
\cline { 3 - 6 } & & $\mathrm{M}$ & $\mathrm{S} . \mathrm{D}$ & $\mathrm{M}$ & S.D \\
\hline 1 & It is easy to access the Alimi site. & 2.23 & 1.11 & 2.40 & 1.19 \\
2 & It is easy to use information in the Alimi site. & 2.22 & 1.10 & 2.30 & 1.03 \\
3 & Information can be analyzed by colleges. & 2.24 & 1.05 & 2.10 & 0.97 \\
4 & Information can be analyzed by majors. & 2.21 & 1.03 & 2.25 & 1.07 \\
& Detailed guidelines about how to use the Alimi site are & 2.21 & 1.05 & 2.20 & 0.95 \\
& provided in the Alimi site. & 2.19 & 1.09 & 2.05 & 0.94 \\
6 & The Alimi site hardly causes the problems. & 2.22 & 1.07 & 2.22 & 1.03 \\
& \multicolumn{2}{c}{ Averages } & & &
\end{tabular}

\subsection{Analysis of Interview Results}

According to the group interview with five university professors, all five knew of the Alimi website and had experiences utilizing the site. Specifically, when they are involved in the college assessment or national projects, they use information in the Alimi site a lot 
and all of them agreed that information disclosure is strongly required but the Alimi website failed to provide the required information. The Alimi website should allow incoming students and their parents to access accurate and detailed information about institutions, information relating to institutions' financial condition, and governmental support for institutional finances. Moreover, information should be easy to process after selecting the required information from the website. For example, information about same or similar majors should be analyzed on an institutional basis with multiple years of information. From the perspective of business organizations, information would also be useful if information on a job applicant's school could be easily compared and analyzed. It also would be useful for assessing professional education offered by institutions. The interviewees also emphasize that accuracy of the data is very important. Therefore, the Alimi site should be updated with the latest information on a regular basis, provided in API formats for easy comparison analysis, and special efforts are required to make the data more understandable by the general public. Furthermore, the sources and effective dates of the data should be recorded in order to ensure the reliability of the data.

\section{Summary}

The purpose of this study was to determine how the Alimi site is utilized and perceived from the perspective of information users and analyze the current state of information utilization as provided by the Alimi site. In order to analyze the current state of information as provided by Alimi, information usage databases from 2013 (data from 2010-2013), 2014 (data from 2011-2014), and 2015 (data from 2012-2015) were used.

Based on the results of analyzing the search hits, the number of hits increased year by year, with 327,936 hits in 2013, 54,079 hits in 2014, and 669,481 hits in 2015. Despite the fact that the data for 2015 were for the period from January to June, the number of hit was higher than for 2014; this shows that the utilization of the data is increasing rapidly.

According to a monthly analysis of the number of hits, April had the highest number of hits at 476,620 hits, and July (76,120 hits), February (81,565 hits), and March (86,640 hits) had the least number of hits compared to other months. Based on analyzing the number of hits by item, in 2013 and 2014, tuition status was the most viewed; in 2015, the students' dropout rates were the most viewed. On a yearly basis, in 2013, the employment status of graduates, freshmen enrollment, research track record of full-time staff, status of current students, and enrolment rates for current students were the most viewed. In 2014, the employment status of graduates, freshmen enrolment, percentage of staff instructing classes, status of current students, and research track record of full-time staff were the most viewed, and in 2015, the status of tuition, employment status of graduates, current student enrolment rates, research track record of full-time staff and the status of current students were the most viewed.

According to the monthly number of hits for the top three viewed items, in 2013, the status of tuition was viewed the most in August and December, the employment status of graduates in September, and the freshmen enrolment rate in July. In 2014, the status of tuition was viewed the most in September and December and the employment status of graduates and freshmen enrolment was viewed the most in September. In 2015, the students' dropout rates was the most viewed in April (380,123 views), which was an anomalous result. The 10 least viewed items were items related to budget and settlement of accounts, tuition accounting, meeting minutes of the tuition committee, the criteria for determining educational fees per student, the status of enrolment screening fees, entrepreneurship support for staff, and management of dormitories.

To determine if the disclosed information was utilized for decision-making in choosing higher education institutions, a survey was conducted with university students and high school teachers responsible for college admissions advising that indicated that the disclosed information was not utilized because they did not know about the Alimi site. 
Among university students and high school teachers, the level of recognition of Alimi was very low: average scores were 1.56 and 2.25 , respectively. The university students had barely heard of the Alimi website and did not know the items and indicators on the site. In terms of the teachers, they had heard of the site, but had not heard of the items and indicators on the site.

According to a group interview with five university professors, all of the professors knew the Alimi site well and had experience using the site. However, they suggested that the data be presented in a format whereby the general public could easily access the data, that information such as employment rates be presented on a comparative basis by faculty or by institution, and that the data be provided to business organizations so that they can easily compare institutional information for job applicants.

\section{Recommendations}

The study found that the Alimi system is mostly used when information is input by institutional administrations and when higher education institution assessments are taking place. In the case of students and teachers, they are not aware of the fact that college information is disclosed to the public. In the case of college professors, they were aware of the Alimi site but they only utilized the information when they were involved in the work relevant to evaluation metrics for their institutions.

As the research was carried out in the limited environment of the $\mathrm{K}$ region and targeted a small number of study participants, it is true that the results do not display generality or representativeness. However, the study was based on a very general target and it is thereby expected that university students, high school teachers, and university staff in other regions would have similar tendencies as well. According to the "2014 Survey on the Satisfaction of Consumers for Higher Education Information Disclosure" conducted by Ahn et al. (2014), the information on Alimi was found to be highly satisfactory, with high school teachers rating it a score of 89.7 , university personnel rating it 89.4 , high school students rating it 88.9 , university students rating it 87.8 , industry personnel rating it 87.6 , and parents of students rating it 86.3. However, it is unclear how the survey participants of 206 university students, 111 high school teachers, and 114 industry professionals were sampled; moreover, the results come from a limited and specialized group of consumers who consisted of 598 parents who had visited the higher education institutions and 847 high school students. Considering that information consumers are spread across the nation, it is important to reconsider whether these levels of satisfaction are sufficiently representative.

Every year, the government allocates a substantial budget to fulfilling citizens' right to know and satisfying the demand for information; research on information disclosure is carried out yearly and improvements in the accessibility and utilization of the Alimi website have been sought. However, the reality is that information on the disclosed information remains lacking from the perspective of the general consumer. Although the provision of necessary educational information for the consumer is sufficient, consumers do not understand that such information is provided due to a lack of knowledge. Even when consumers understand that information is provided, a lack of interest prevents the utilization of this information. The data on the Alimi website are provided in their original Excel form to allow for comparative analyses by item, faculty, and institution; however, users still suggested that these functions be added. In order to improve the recognition and utilization of the Alimi website, the following suggestions are proposed.

\subsection{Providing Ongoing Marketing and Site Utilization Training Sessions for High Schools}

Every year, the Korean Council for University Education publishes guidelines on using the Alimi website, which are distributed to universities and institutions. While some 
interested users have referenced these guidelines, many are not even aware of the fact that the guidelines are being published. According to the number of search hits from this study, the data are most often viewed during periods when institutional personnel are entering data or when institutions are being assessed. However, for students and their parents, the demand for information on universities is extremely high. Although high school teachers need to provide objective information on universities to students and their parents for them to reference when they make choices regarding enrolment, these teachers are not even aware of, and do not utilize, the Alimi website. Therefore, yearly advertisements for the Alimi website targeting high schools and site utilization training sessions for high school teachers are necessary. The students and parents who participated in the study by Ahn et al. (2014) were participants in university information sessions. It is obvious that these participants, whose primary interest was university enrollment, would be highly interested in the data from the Alimi website. Therefore, advertising the site through information sessions is also very important. Consistent yearly site advertisements targeting high schools as well as utilization training will effectively increase the number of consumers for the Alimi site.

\subsection{Simplifying Comparison and Search Methods for University Information Consumers}

At universities, data comparing faculties and institutions are in high demand. At present, even if certain majors in the same discipline are searched for, if naming conventions or classifications are different, it is difficult to bring together the major search results from all institutions to the comparison page. Although it is possible to compare majors and institutions, if majors belong in different colleges or specialization is different, they are not classified as part of the same faculty. For example, in terms of social welfare studies, searching for social welfare studies results in more than 20 sub-majors and cross-searching for nationwide social welfare faculties is impossible. In the case of real estate surveying, some institutions classify it under management and other institutions classify it under urban planning and geography. Therefore, even if the major is the same, the sub- and main classifications are different, leading to difficulties in searching for faculties. To solve this problem, a standard code for majors should be assigned when data are input and the same code should be used for similar faculties.

The purpose of higher education information disclosure is to disseminate information relating to higher education, such as its conditions, processes, and achievements, to ensure that citizens' right to know is fulfilled, and to enable policymakers to utilize this data as a trustworthy source in policy making and assessments. However, as mentioned in this study, users other than policymakers, administrative personnel who input data for universities, and professors involved with assessments do not enjoy the benefits of this disclosed information. Therefore, solutions facilitating active advertising to help general consumers of this information effectively access this information and to enable users to effectively utilize this information based on their unique demands are required.

\section{References}

[1] C. Byun, H. Lee and H. Shin, "Editors. The Influence of Twitter: Super Bowl Commercial through Social Network", Proceedings of International Conferenced of the Science and Engineering Support Society, Hochimin, Vietnam, October 24-26, (2014).

[2] Y. K. Hwang, "Aspect of Colleges about Information Disclosure Systems”, College Education, vol. 158, (2009).

[3] J. W. Ko, "Editor, 2014 College Information Disclosure 2014”,, Korean Center for University Education, Seoul, (2014).

[4] S. K. Kim, "Achievement and Tasks of School Information Disclosure Systems", Education Policy, vol. 221, (2009).

[5] Korean Education Development Institute, "College Information Disclosure System", How Do We Handle?, KEDI, Seoul, (2009). 
[6] Korean Education Development Institute, "Ways of Developing Educational Information Disclosure Systems", KEDI, Seoul, (2008).

[7] Korean Education Development Institute, "Educational Statistics and Research on the Management and Utilization of Disclosed Information", KEDI, Seoul, (2009).

[8] K. M. Lee, "Research on the Information Consumer Oriented College Information Disclosure Policies: Focusing on the Alimi Cases", Joongang University, Seoul, (2011).

[9] H. Moon, J. Kim, S. Han and J. Choi, "Editors. A Reference Model of Smart Library", Proceedings of International Conferenced of the Science and Engineering Support Society, Hochimin, Vietnam, October 24-26, (2014).

[10] S. H. Oh and S. D. Choi, "Examining the Logical Ways of Operating the Educational Information Disclosure Systems", Korean Regional Administration Research, vol. 28, (2008).

[11] J. H. Park, "Issues and Tasks of College Education and Financial Support for Colleges", Korean Center for University Education 47th Policy Forum, Seoul, Korea, October 23, (2014).

[12] J. S. Park, Y. Lee, Y. K. Han and S. J. Hong, "Research on Effective Ways of Managing Participation Based College Information Systems", Ministry of Education, Seoul, (2010).

[13] H. J. Park, "Issues and Tasks of Educational Information Disclosure of Higher Education Institutes", Education Development, vol. 35, (2008).

[14] J. Seo, I. Khan and J. Choi, "Editors. Educational Data mining: an Application of Data Mining Techniques With the Educational Web-based System for Predicting Student Performance", Proceedings of International Conferenced of the Science and Engineering Support Society, Hochimin, Vietnam, October 24-26, (2014).

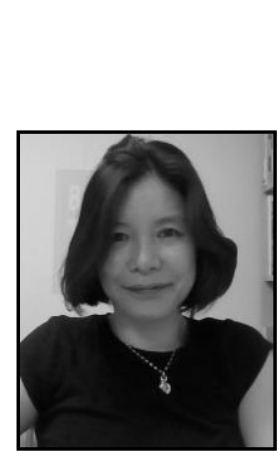

\section{Author}

Eunjoo Oh, she is a professor in the department of Library and Information Science at the Kyungil University in Korea. Eunjoo has a doctorate in Instructional Technology from the University of Tennessee, Knoxville, U.S.A. Her research interests include instructional design, blended learning, and information behaviors. 
International Journal of Multimedia and Ubiquitous Engineering

Vol.10, No.10 (2015) 